\title{
Antipsychotic medications and cognitive functioning in bipolar disorder: moderating effects of COMT Val ${ }^{108 / 158}$ Met genotype
}

Baer Arts $^{1 *}$, Claudia JP Simons ${ }^{1,2}$, Marjan Drukker ${ }^{1}$ and Jim van Os ${ }^{1,3}$

\begin{abstract}
Background: There is a negative association between the use of antipsychotics and cognitive functioning in bipolar patients, which may be mediated by altered dopamine signaling in selected brain areas, and moderation thereof by genetic sequence variation such as COMT Val ${ }^{108 / 158} \mathrm{Met}$. The interaction between antipsychotic drug use and the COMT Val ${ }^{108 / 158}$ Met genotype on two-year cognitive functioning in bipolar patients was examined.

Methods: Interaction between the COMT Val ${ }^{108 / 158}$ Met and antipsychotics on a composite cognitive measure was examined in 51 bipolar patients who were assessed 12 times at two-monthly intervals over a period of two years (379 observations).

Results: There was a significant negative effect of the interaction between antipsychotic medications and Val allele load on the composite cognitive measure in bipolar patients $(p<0.001)$.

Conclusions: The negative effects of antipsychotics on cognitive functioning in bipolar disorder may be moderated by the COMT Val ${ }^{108 / 158}$ Met genotype, with a negative effect of Val allele load. If replicated, the results may be indicative of pharmacogenetic interactions in bipolar disorder.
\end{abstract}

Keywords: Bipolar disorder, Cognition, Antipsychotics, COMT

\section{Background}

Meta-analyses of neuropsychological functioning in euthymic bipolar patients suggest that generalized, rather than specific, cognitive impairments may exist, characterized by substantial heterogeneity that is not fully explained by demographic, illness and medication variables [1-4]. Nevertheless, reviews point to a possible role for antipsychotics, indicating that antipsychotics may have detrimental impact on cognitive functioning in bipolar patients [5]. For example, Jamrozinski and colleagues (2008) reported no differences between euthymic bipolar patients not exposed to antipsychotic treatment and healthy controls on any neuropsychological measure, whereas a significant underperformance was apparent in

\footnotetext{
* Correspondence: b.arts@maastrichtuniversity.nl

'Department of Psychiatry and Psychology, School for Mental Health and Neuroscience, European Graduate School of Neuroscience (EURON), South Limburg Mental Health Research and Teaching Network (SEARCH), Maastricht University Medical Centre, P.O. Box 616 (DRT 12), Maastricht, MD 6200, The Netherlands

Full list of author information is available at the end of the article
}

the bipolar group treated with antipsychotics [6]. A more recent study showed dose-independent deficits in several cognitive tasks in euthymic bipolar patients treated with quetiapine, olanzapine or risperidone, with worse performance in patients on second generation antipsychotics compared to untreated euthymic patients [7]. A recent 2-year naturalistic study on cognitive functioning in bipolar patients showed significant variation of cognitive functioning over time, largely independent of clinical factors, with the exception of antipsychotic drug use impacting negatively on tasks indexing speed of information processing [8]. The suggested negative effects of antipsychotics on cognition in bipolar patients contrast with the apparently positive, cognition-enhancing effects of these drugs in the treatment of schizophrenia and schizoaffective disorder [9-12]. However, cognitionenhancing effects in schizophrenia may at least in part be attributable to practice effects $[13,14]$. Cognitive effects of antipsychotics may be mediated by alterations in dopamine signaling in selected brain areas. It may be 
hypothesized that in altered and/or hyperdopaminergic states, which may underlie schizophrenia symptoms [15], antipsychotic drugs improve cognition, whereas in bipolar patients without hyperdopaminergia, antipsychotic treatment may induce suboptimal cognitive functioning [6].

Antipsychotic effects impacting on dopamine signaling may be modulated by genetic sequence variation. The COMT (catechol-O-methyltransferase) gene $\mathrm{Val}^{108 / 158} \mathrm{Met}$ polymorphism modulates dopaminergic function in frontostriatal circuitry, and may impact information processing efficiency, due to its critical role in the enzymatic degradation of dopamine. The Val/Val genotype is associated with greater activity of the enzyme and hence with lower concentrations of dopamine in the prefrontal cortex $[16,17]$. Furthermore, in patients with schizophrenia, an interaction of the COMT Val ${ }^{108 / 158}$ Met genotype and antipsychotic treatment on cognitive functioning has been reported, Met allele load predicting better cognitive performance [18-21], especially in tasks requiring effortful cognitive control [22].

The aim of the present study was to examine whether COMT $\mathrm{Val}^{108 / 158}$ Met genotype modulates the effect of antipsychotics on a composite cognitive measure, indexing effortful cognitive control, in a sample of bipolar patients, hypothesizing a detrimental effect of Val allele load.

\section{Methods}

\section{Subjects}

Individuals were participants in the BIPOLCOG (BIPOLar and COGnition) study [23], a study on cognitive functioning in bipolar disorder (BD) in which three groups were investigated: (i) patients with bipolar disorder, (ii) healthy first-degree relatives of patients with bipolar disorder, and (iii) healthy control participants. All subjects were white, between the ages of 18 and 60 years, fluent in Dutch, had an IQ $>70$ and were without a history of neurological disorders such as epilepsy and concussion with loss of consciousness. For the purpose of the current report, only the bipolar patient group was studied, with the healthy control group as reference.

A representative cohort of successively attending patients with a diagnosis of bipolar spectrum disorder according to DSM-IV [24] were recruited through the in-patient and out-patient mental health facilities in the geographically defined catchment area of South Limburg. In addition, patients were recruited through the local association of bipolar patients and their families, in order to also include patients not currently in contact with services. The computer program OPCRIT was used to confirm DSM-IV diagnosis on the basis of current and lifetime recorded symptomatology listed in the Operational Criteria Checklist for Psychotic Illness, scored by the clinical researcher on the basis of all interview and historical case note data (OCCPI) [25].

Control subjects were recruited from the general population using a random mailing sampling procedure and were clinically and diagnostically interviewed with The Comprehensive Assessment of Symptoms and History (CASH) [26] and OPCRIT criteria to exclude those with a past or current diagnosis of $\mathrm{BD}$ or psychotic disorder. Healthy controls were additionally interviewed with the Family Interview for Genetic Studies (FIGS) [27] in order to confirm the absence of a family history of psychotic or bipolar disorder.

The initial sample consisted of 81 patients and 61 healthy control subjects. Three patients were excluded because data on diagnosis were missing. Neuropsychological testing data were missing for two patients. The last filter concerned incomplete or missing genetic data, leaving a final risk set for analysis of 51 patients and 50 healthy controls.

\section{Procedure}

As cognitive alterations in bipolar disorder largely develop after onset of illness [28], longitudinal assessment is necessary to adequately capture the phenotype. Thus, patients were examined at 2-monthly intervals over a period of 2 years, yielding a maximum of 12 assessments. At all time points, neuropsychological testing and psychiatric interviewing took place and questionnaires were completed (regarding social functioning, medication, use of drugs etc.). Genetic material was collected at the first visit. During the baseline interview, basic demographic information was collected as was information on illness characteristics.

The study was performed in conformity with the Declaration of Helsinki, and approved by the Ethics Committee of the Maastricht University and Academic Hospital. All subjects gave written informed consent prior to participation.

Neuropsychological tests and psychiatric interviews were conducted by trained psychologists, each interview occasion taking approximately 2 hours to complete.

Healthy controls, in whom cognition is more stable than in patients, were tested twice at two monthly intervals. Data on healthy controls were used as reference to calculate standardized z-scores.

\section{Neurocognitive assessment}

Neurocognitive tests were administered by computer, using E-prime for Windows on a 15-inch monitor Toshiba Tecra laptop. The test battery included tasks measuring various neurocognitive domains, guided by previous evidence of impaired performance in these domains in bipolar patients [1,2]. Three subtests were selected a priori from the original test battery, described 
elsewhere [8], representing tasks with high cognitive load that previous work suggests are most sensitive to moderation by sequence variation in COMT [29-31].

Overall intellectual functioning was estimated at baseline using three Groningen Intelligence Test (GIT) subtests (Mental Rotation, Word Analogies and Mental Arithmetic) [32], yielding results that are comparable to those of the Wechsler Adult Intelligence Scale III [33].

Verbal learning and memory was assessed with the standardized Dutch version of the visually-presented Verbal Learning Test [34,35]. In three consecutive trials, 15 monosyllabic non-related words had to be memorized and reproduced. Delayed recall was measured after a 20-minute delay. Parallel versions of this test were used, in order to avoid test-retest-effects.

The Flanker CPT (Cogtest plc, London) [36] is a measure of selective visual control of attention. Subjects are instructed to respond by pressing the right or left mouse button depending on whether the middle element in a display of five lines has an arrowhead pointing to the right or left. There are three trial types: (i) neutral trials in which the flankers are just horizontal lines without arrowheads, (ii) congruent trials in which all flankers have an arrowhead pointing in the same direction as the target, and (iii) incongruent trials, in which flankers are pointing in the opposite direction from the target. The incongruent condition involves more cognitive effort, because the flankers are associated with a response that needs to be suppressed (measure of response inhibition). One-half of the trials was presented with the stimuli above the fixation cross and the other half were presented below fixation, in order to prevent the subjects from keeping their gaze fixed in one position. The test consisted of 144 trials of neutral, congruent and incongruent flankers, which were presented randomly. Outcome measure was the mean reaction time for correct responses (RT) in the incongruent condition.

Finally, Digit Span Backward of the Wechsler Intelligence Scale III [37] was used as measure of working memory.

All 3 cognitive measures were standardised, higher scores reflecting better performance. In order to calculate a measure of global cognitive functioning, raw test scores were converted into standardized z-scores against the means and standard deviations of the healthy control group. The final composite measure of neurocognition was based on the means of the three domain scores, representing effortful information processing (verbal memory, selective attention/response inhibition and working memory).

\section{Genotyping}

Buccal swab samples were obtained followed by SNP analysis. For the current analysis, the COMTVal ${ }^{108 / 158} \mathrm{Met}$ rs4680 was selected a priori because this is the only SNP that is consistently associated with antipsychotics in pharmacogenetic models $[18,19]$, making it the only credible candidate. Although more SNPs had been determined ( $n=184$ ), these formed part of a standard set for the study of gene-environment interactions $(\mathrm{GxE})$, based on published findings up to April 2009 (for the rational underlying this selection process and an overview of selected SNPs see [38]). The 184 SNPs had been chosen $a$ priori (i.e. were not selected from a larger set of genomewide markers) and selectively determined by Sequenom (Hamburg, Germany) using the Sequenom Mass ARRAY iPLEX platform at the facilities of the manufacturer. In accordance with a priori quality control criteria of the GROUP study, SNPs with more than $10 \%$ genotyping errors were excluded, as were SNPs in marked HardyWeinberg disequilibrium ( $\mathrm{p}<0.001)$.

\section{Statistical analysis}

Regression analyses were carried out using the statistical software program STATA (version 11.2) [39]. In the bipolar patient group, the moderating effect of Val allele load on the cognitive effects of antipsychotic medications was analysed on the 3 separate cognitive tasks, as well as on the composite cognitive measure. The Bonferroni correction for multiple testing was applied, yielding a corrected p-value for significance of $\mathrm{p}<0.00625(0.05 / 8)$.

Data were hierarchical with multiple observations (interview occasion or time; level 1) clustered within subjects (level 2). Data, including the demographic and cognitive data, were analysed using the STATA XTREG multilevel regression routine. The analyses of the interaction between the COMT Val allele load and antipsychotics on cognitive functioning were a priori adjusted for the confounding effects of demographic characteristics (age, sex, education), symptoms (BPRS, HDRS, YMRS), and time as fixed factors.

Dummies were constructed for Val allele load with value 0 for the Met/Met genotype and value 1 for the combination of the $\mathrm{Val} / \mathrm{Met}$ and $\mathrm{Val} / \mathrm{Val}$ condition. The $\mathrm{Val} / \mathrm{Met}$ and $\mathrm{Val} / \mathrm{Val}$ conditions were combined because of the small number of observations in the Val/Val condition. Finally, dummies were constructed for the medication variable with value 1 for using antipsychotics and value 0 for not using this type of medication. Stratified effects were calculated from the model containing the interaction, using the STATA MARGINS command.

\section{Power analysis}

Power of the analysis was calculated by simulation from an example on the Stata website (http://www.stata.com/ support/faqs/stat/power.html). Because these simulations cannot be performed in multilevel data, the unilevel equivalent of the $n$ of the multilevel data set was 
calculated using the following formulaes [40].

$$
\begin{aligned}
& \text { MF }=1+(9-1) * 0.6=5.8 \\
& \text { uen }=51 * 9 / 5.8=79
\end{aligned}
$$

In which 9 is the number of assessments per person, 51 is the number of persons and 0.6 is the intra class correlation. The power of our sample size of $n=79$, alpha $=0.00625$ and a large effect size $(0.8 \mathrm{sd})$ was 0.10 .

\section{Results}

\section{Subjects}

Demographic data, symptom scores and neurocognitive test results are presented in Table 1 . There were no significant differences between the two groups (Met/Met versusVal/Met plus Val/Val) after Bonferroni correction $(\mathrm{p}<0.00625)$. However, the combined Val/Met plus Val/ Val group performed better on the working memory task than the Met/Met group (beta: $1.15 ; \mathrm{p}=0.033$, i.e. not Bonferrone corrected). Thirteen of the 51 patients used antipsychotic medications during the two-year period of our study; these patients contributed 38 observations. Allele frequencies were $56 \%$ for the Met allele and $45 \%$ for the Val allele, respectively.

\section{Genotype}

Twelve patients were homozygous for the Met allele, 32 patients were heterozygous and 7 patients were homozygous for the Val allele. Genotypes in the bipolar group were in Hardy-Weinberg equilibrium $(P>0.09)$.

Table 1 Demographics, psychopathology and neurocognitive testresults of COMT Val/Met rs4680 in

\begin{tabular}{|c|c|c|c|c|}
\hline & \multicolumn{2}{|c|}{$\begin{array}{l}\text { Met/Met } \\
(\mathrm{N}=12 ; 92 \text { obs.) }\end{array}$} & \multicolumn{2}{|c|}{$\begin{array}{l}\text { Val/Met + Val/Val } \\
(\mathrm{N}=39 ; 355 \text { obs.) }\end{array}$} \\
\hline & Mean & SD & Mean & SD \\
\hline Gender M/F & $7 / 5$ & & $20 / 19$ & \\
\hline Age & 45.5 & 8.7 & 46.5 & 6.8 \\
\hline Education & 4.6 & 2.4 & 5.5 & 2.2 \\
\hline $\mathrm{BPRS}^{1}$ & 1.3 & 0.2 & 1.3 & 0.2 \\
\hline $\mathrm{HDRS}^{2}$ & 2.9 & 3.6 & 3.3 & 3.9 \\
\hline $\mathrm{YMRS}^{3}$ & 2.1 & 3.2 & 1.1 & 2.3 \\
\hline GIT-IQ & 101.7 & 9.7 & 110.5 & 13.3 \\
\hline Verbal memory & 7.2 & 2.4 & 8.2 & 3.7 \\
\hline Selective attention & 729.5 & 77.4 & 687.6 & 81.9 \\
\hline Working memory & 5.7 & 1.6 & 6.9 & 2.1 \\
\hline Antipsychotic use & 5 & & 8 & \\
\hline
\end{tabular}
bipolar patients

${ }^{1}$ Brief Psychiatric Rating Scale.

2 Hamilton Depression Rating Scale.

3 Young Mania Rating Scale.

\section{Cognitive data}

The interaction between COMTVal ${ }^{108 / 158}$ Met Val allele load and antipsychotics on two-year cognitive functioning in bipolar patients is presented in Table 2. As evidenced in this table, there exists a detrimental effect of Val allele load on the cognitive effects of antipsychotic medications. The composite cognitive measure survived Bonferroni correction.

\section{Discussion}

\section{Summary of findings}

Patients with bipolar disorder displayed a negative modulating effect of COMT Val ${ }^{108 / 158}$ Met Val allele load on the effects of antipsychotics on two-year cognitive functioning. Given the small number of patients, this finding must be considered preliminary. Replication of this underpowered, hypothesis-generating study, would require a number of 193 patients in order to obtain a power of 0.8 (given the small number of patients using antipsychotics). Alternatively, increasing the number of patients using antipsychotics would increase power too. Nevertheless, the results, if replicated, suggest a gene-by -environment interaction between antipsychotic medications and COMT Val ${ }^{108 / 158}$ Met rs 4680 . Patients with a more severe course of illness may be more likely to receive antipsychotic medications; however, post-hoc analyses revealed no significant effects of number of episodes and/or psychotic symptoms in the past on the interaction between antipsychotics and Val allele load. Furthermore, post-hoc analyses yielded no significant interactive effects of $\mathrm{Val}$ allele load on tasks requiring less cognitive effort, such as sustained attention and motor speed.

\section{Interaction between antipsychotics and COMT $\mathrm{Val}^{108 / 158}$ Met on cognitive functioning}

Our finding of a negative effect on cognition of antipsychotics in Val allele carriers is in line with the sparse literature in patients with schizophrenia. RebolloMesa et al. (2011), for instance, report a negative effect on cognition in Val/Val homozygotes using antipsychotics in contrast with a reversed association in Met/Met carriers [21]. Furthermore, a positive effect of antipsychotics on cognitive functioning in Met allele carriers with schizophrenia is described in the literature, with no evidence of improvement of cognition in Val allele carriers using antipsychotics, thus indicating interactive effects [18-20]. These findings support the hypothesis of Jamrozinski et al. (2009) of differential effects of antipsychotics on cognitive functioning depending on basal dopamine levels, antipsychotics lowering dopamine functioning and inducing suboptimal cognitive status in bipolar patients with already lower basal dopamine levels, as is the case in Val allele carriers [6]. 
Table 2 Interaction between antipsychotic medications and COMT Val/Met polymorphism (rs4680) on cognitive functioning in bipolar patients (Met/Met as reference; psychopathology and time as fixed factors)

\begin{tabular}{llllllllll}
\hline Cognitive & Variable & Verbal & Memory & Selective & Attention & Working & Memory & Composite & Measure \\
\hline N obs. & & 419 & & 384 & & 416 & & 379 & b-value \\
& & beta & p-value & beta & p-value & beta & p-value & beta & 0.036 \\
COMT & & 0.24 & 0.511 & 0.63 & 0.053 & 0.5 & 0.051 & 0.42 & 0.19 \\
Antipsych. & & -0.03 & 0.932 & 0.64 & 0.087 & 0.05 & 0.858 & -0.367 \\
MainInteract. & & -0.79 & 0.091 & -1.1 & 0.024 & -0.35 & 0.340 & -0.79 & 0.004 \\
Stratified & COMT $=0$ & & & 0.64 & 0.087 & & 0.19 & 0.367 \\
interaction & COMT $=1$ & & & -0.47 & 0.141 & & -0.59 & 0.001 \\
BPRS & & -0.05 & 0.492 & -0.02 & 0.835 & -0.05 & 0.396 & -0.04 & 0.385 \\
HDRS & & 0.005 & 0.948 & 0.05 & 0.551 & 0.06 & 0.292 & 0.02 & 0.602 \\
YMRS & & 0.002 & 0.972 & 0.12 & 0.029 & 0.07 & 0.061 & 0.06 & 0.063 \\
Time & & 0.06 & 0.000 & 0.13 & 0.000 & 0.09 & 0.000 & 0.09 & 0.000 \\
\hline
\end{tabular}

\section{COMTVal ${ }^{108 / 158}$ Met rs4680 and cognitive functioning}

In general, the COMT $\mathrm{Val}^{108 / 158}$ Met polymorphism appears to have little if any direct association with cognitive functioning [41], with mixed results in patients with schizophrenia [42,43] and bipolar disorder [29,31], as well as in healthy controls $[44,45]$. Krabbendam et al. (2006) suggest indirect (positive) effects of Met allele loading on cognitive functioning, independent of schizophrenia liability, through gene-gene interactions or the influence of a functional polymorphism near COMT Val ${ }^{108 / 158}$ Met [46]. The latter is illustrated by the study of Burdick et al. (2007), finding no association between COMTrs4680 and cognitive functioning, but an association between cognitive functioning and COMTrs165599 in bipolar patients and healthy controls [47]. Furthermore, Diaz-Asper and colleagues (2008) report a negative effect of the Val allele on cognitive functioning, irrespective of diagnosis, and significant effects on cognition of other COMT haplotypes, for instance COMTrs737865 [30]. Finally, the literature supports the possible role of gene-gene interactions on cognitive functioning due to epistatis between COMT and several other gene polymorphisms, impacting dopamine signalling [48-50], GABAergic functioning $[51,52]$ and glutamatergic systems [53,54], amongst others.

In conclusion, COMT most likely has indirect effects on cognitive functioning by modulating dopaminergic neurotransmission, influencing attentional network efficiency [55], amongst others, with a possible advantage of the Met allele on effortful cognitive control or conflict processing, not supporting a simple stability/flexibility model of dopamine COMT Val/Met effects, according to Rosa et al. [22].

\section{COMTrs4680 and dopamine function}

The dual state, or tonic-phasic dopamine theory hypothesizes that the COMT Met allele results in increased levels of dopamine and a tonic D1-dominated state in the prefrontal cortex, thus increasing signal-to -noise ratio in prefrontal attractor states that may improve performance in some measures, such as working memory, but not others $[16,56,57]$. The latter is illustrated by the meta-analysis of neuroimaging studies of COMTrs4680 by Mier et al. (2010), reporting a significant association between the COMT genotype and prefrontal activation (effect size: 0.73), with opposing effects for executive cognition paradigms, favouring Met allele carriers, and emotional paradigms, favouring Val allele carriers [58]. These pleiotropic effects of COMT4680 on neural mechanisms underlying cognitive functioning are further illustrated by recent (f-)MRI-studies, showing evidence for COMTgenotype-dependent differences in amygdala responsivity and connectivity [59-61] and prefrontal cortex activation and connectivity patterns, including default network [62-64]. Finally, COMT haplotypes, other than Val/Met, can nonlinearly modulate intelligence-related white matter integrity of the prefrontal lobes by significantly influencing prefrontal dopamine variations, fitting an inverted U-model [65].

\section{Dopamine and cognitive functioning}

The evidence for the inverted U-model of the dopamine actions on cognitive functioning, especially working memory and cognitive control, is reviewed by Cools et al. (2011). These authors conclude that there exists an optimum dopamine level for different cognitive functions, implicating the importance of baseline levels of dopamine, where both too little and too much dopamine may impair performance, depending on a dynamic balance between cognitive stability (prefrontal cortex) and cognitive flexibility (striatum) [66,67]. Prefrontal dopamine D1 receptor activation, in this respect, may improve sustained attention [68], whereas striatal dopamine D2 receptor signalling may be associated with cognitive flexibility [69], with a 
central role for dopamine in effort-based decision making [70] and the interaction between appetitive motivation and cognition [71], amongst others. The inverted U-shaped curve of dopamine's action is influenced by (uncontrollable) stress, weakening prefrontal cortex functioning [72], as well as influencing stress-related methylation of the gene, partially compensating the role of the high-activity Val allele in prefrontal cognition [73]. Furthermore, estradiol status and working memory load, which may potentiate dopamine and thus have beneficial effects for Val homozygotes and unfavourable effects for Met homozygotes, may play a role as well [74]. In contrast, Karlsson et al. (2011), found no linear or curvilinear relationships between dopamine D1 receptor binding in dorsolateral prefrontal cortex and performance in any cognitive task, providing support for the notion that D1 receptors in separate brain regions are differentially related to performance in various cognitive tasks [75].

\section{Methodological considerations}

The results should be interpreted in the light of several limitations. First, the small number of patients and observations regarding exposure to antipsychotic medications, makes our results preliminary, needing replication in larger samples. Results therefore can be considered as hypothesis-generating. Second, the effects of possible confounders such as gene-gene interactions, the influence of functional polymorphisms near COMT $\mathrm{Val}^{108 / 158} \mathrm{Met}$, epigenetic changes due to stress and/or medication, task demands, and the possible interaction between COMT $\mathrm{Val}^{108 / 158}$ Met and herpes simplex virus type 1 infection [29], amongst others, were not adequately controlled for in our study.

The longitudinal character of our study, however, may have been more sensitive to genetic effects, in this case the interaction between COMT Val ${ }^{108 / 158}$ Met Val allele load and antipsychotic medication, given the significant variation of cognitive functioning over time in bipolar patients [8].

\section{Conclusions}

The negative effects of antipsychotic medication on cognitive functioning in patients with bipolar disorder, may be partly moderated by COMT Val ${ }^{108 / 158}$ Met Val allele load. This finding agrees with an indirect, modulatory role for COMT on (basal) dopamine levels in different brain areas, relevant for (effortful) cognitive functioning, thus influencing the cognitive side-effects of antipsychotics in patients with bipolar disorder.

\section{Competing interests}

Baer Arts none.

Claudia Simons none.

Marjan Drukker none.
Jim van Os is/has been an unrestricted research grant holder with, or has received financial compensation as an independent symposium speaker from Eli Lilly, BMS, Lundbeck, Organon, Janssen-Cilag, GSK, AstraZeneca, Pfizer and Servier, companies that have an interest in the treatment of psychosis.

\section{Authors' contributions}

All the authors of the article have participated in: 1) making substantial contributions to conception and design, or acquisition of data, or analysis and interpretation of data; 2) writing the drafts of the manuscript or revising them critically for important intellectual content; and 3) giving final approval of the version to be published.

\section{Acknowledgements}

This study was supported in part by unrestricted grants from Astra Zeneca, The Netherlands, and Eli Lilly, The Netherlands.

\section{Author details}

${ }^{1}$ Department of Psychiatry and Psychology, School for Mental Health and Neuroscience, European Graduate School of Neuroscience (EURON), South Limburg Mental Health Research and Teaching Network (SEARCH), Maastricht University Medical Centre, P.O. Box 616 (DRT 12), Maastricht, MD 6200, The Netherlands. ${ }^{2}$ GGZE, Institute for Mental Health Care Eindhoven en de Kempen, P.O. Box 909, Eindhoven, AX 5600, The Netherlands. ${ }^{3}$ King's College London, King's Health Partners, Department of Psychosis Studies, Institute of Psychiatry, London, United Kingdom.

Received: 6 June 2012 Accepted: 8 February 2013

Published: 19 February 2013

\section{References}

1. Arts B, Jabben N, Krabbendam L, Van Os J: Meta-analyses of cognitive functioning in euthymic bipolar patients and their first-degree relatives. Psychol Med 2008, 38(6):771-785.

2. Bora $E$, Yucel M, Pantelis C: Cognitive endophenotypes of bipolar disorder: A meta-analysis of neuropsychological deficits in euthymic patients and their first-degree relatives. J Affect Disord 2009, 113:1-20.

3. Kurtz MM, Gerraty RT: A meta-analytic investigation of neurocognitive deficits in bipolar illness: profile and effects of clinical state. Neuropsychology 2009, 23(5):551-562.

4. Mann-Wrobel MC, Carreno JT, Dickinson D: Meta-analysis of neuropsychological functioning in euthymic bipolar disorder: an update and investigation of moderator variables. Bipolar Disord 2011, 13(4):334-342.

5. Balanza-Martinez V, Selva G, Martinez-Aran A, Prickaerts J, Salazar J, Gonzalez-Pinto A, Vieta E, Tabares-Seisdedos R: Neurocognition in bipolar disorders-a closer look at comorbidities and medications. Eur J Pharmacol 2010, 626(1):87-96.

6. Jamrozinski K, Gruber O, Kemmer C, Falkai P, Scherk H: Neurocognitive functions in euthymic bipolar patients. Acta Psychiatr Scand 2009, 119(5):365-374.

7. Torrent C, Martinez-Aran A, Daban C, Amann B, Balanza-Martinez V, Del Mar BC, Cruz N, Franco C, Tabares-Seisdedos R, Vieta E: Effects of atypical antipsychotics on neurocognition in euthymic bipolar patients. Compr Psychiatry 2011, 52(6):613-622.

8. Arts B, Jabben N, Krabbendam L, Van Os J: A 2-year naturalistic study on cognitive functioning in bipolar disorder. Acta Psychiatr Scand 2011, 123(3):190-205.

9. Keefe RS, Bilder RM, Davis SM, Harvey PD, Palmer BW, Gold JM, Meltzer HY, Green MF, Capuano G, Stroup TS, et al: Neurocognitive effects of antipsychotic medications in patients with chronic schizophrenia in the CATIE Trial. Arch Gen Psychiatry 2007, 64(6):633-647.

10. Keefe RS, Sweeney JA, Gu H, Hamer RM, Perkins DO, McEvoy JP, Lieberman $J A$ : Effects of olanzapine, quetiapine, and risperidone on neurocognitive function in early psychosis: a randomized, double-blind 52-week comparison. Am J Psychiatry 2007, 164(7):1061-1071.

11. Woodward ND, Purdon SE, Meltzer HY, Zald DH: A meta-analysis of cognitive change with haloperidol in clinical trials of atypical antipsychotics: dose effects and comparison to practice effects. Schizophr Res 2007, 89(1-3):211-224.

12. Davidson M, Galderisi S, Weiser M, Werbeloff N, Fleischhacker WW, Keefe RS, Boter H, Keet IP, Prelipceanu D, Rybakowski JK, et al: Cognitive effects of antipsychotic drugs in first-episode schizophrenia and schizophreniform 
disorder: a randomized, open-label clinical trial (EUFEST). Am J Psychiatry 2009, 166(6):675-682.

13. Goldberg TE, Goldman RS, Burdick KE, Malhotra AK, Lencz T, Patel RC, Woerner MG, Schooler NR, Kane JM, Robinson DG: Cognitive improvement after treatment with second-generation antipsychotic medications in first-episode schizophrenia: is it a practice effect? Arch Gen Psychiatry 2007, 64(10):1115-1122.

14. Guo X, Zhai J, Wei Q, Twamley EW, Jin H, Fang M, Hu M, Zhao J: Neurocognitive effects of first- and second-generation antipsychotic drugs in early-stage schizophrenia: a naturalistic 12-month follow-up study. Neurosci Lett 2011, 503(2):141-146.

15. Howes OD, Kapur S: The dopamine hypothesis of schizophrenia: version III-the final common pathway. Schizophr Bull 2009, 35(3):549-562.

16. Frank MJ, Fossella JA: Neurogenetics and pharmacology of learning, motivation, and cognition. Neuropsychopharmacology 2011, 36(1):133-152

17. Hariri AR: The what, where, and when of catechol-o-methyltransferase. Biol Psychiatry 2011, 70(3):214-215.

18. Weickert TW, Goldberg TE, Mishara A, Apud JA, Kolachana BS, Egan MF, Weinberger DR: Catechol-O-methyltransferase val108/158met genotype predicts working memory response to antipsychotic medications. Biol Psychiatry 2004, 56(9):677-682.

19. Bertolino A, Caforio G, Blasi G, De Candia M, Latorre V, Petruzzella V, Altamura M, Nappi G, Papa S, Callicott JH, et al: Interaction of COMT (Val (108/158)Met) genotype and olanzapine treatment on prefrontal cortical function in patients with schizophrenia. Am J Psychiatry 2004, 161(10):1798-1805

20. Woodward ND, Jayathilake K, Meltzer HY: COMT val108/158met genotype, cognitive function, and cognitive improvement with clozapine in schizophrenia. Schizophr Res 2007, 90(1-3):86-96.

21. Rebollo-Mesa I, Picchioni M, Shaikh M, Bramon E, Murray R, Toulopoulou T: COMT (Val(158/108)Met) genotype moderates the impact of antipsychotic medication on verbal IQ in twins with schizophrenia. Psychiatr Genet 2011, 21(2):98-105.

22. Rosa EC, Dickinson D, Apud J, Weinberger DR, Elvevag B: COMT Val158Met polymorphism, cognitive stability and cognitive flexibility: an experimental examination. Behav Brain Funct 2010, 6:53.

23. Jabben N, Arts B, Krabbendam L, Van Os J: Investigating the association between neurocognition and psychosis in bipolar disorder: further evidence for the overlap with schizophrenia. Bipolar Disord 2009 11(2):166-177

24. APA: Diagnostic and Statistical Manual of Mental Disorders. Fourthth edition Washington, DC: American Psychiatric Association; 1994.

25. McGuffin P, Farmer A, Harvey I: A polydiagnostic application of operational criteria in studies of psychotic illness. Development and reliability of the OPCRIT system. Arch Gen Psychiatry 1991, 48(8):764-770.

26. Andreasen NC, Flaum M, Arndt S: The Comprehensive Assessment of Symptoms and History (CASH). An instrument for assessing diagnosis and psychopathology. Arch Gen Psychiatry 1992, 49(8):615-623.

27. Maxwell ME: Manual for the family interview for genetic studies (FIGS). Bethesda, Maryland: National Institute of Mental Health; 1992.

28. Goodwin GM, Anderson I, Arango C, Bowden CL, Henry C, Mitchell PB, Nolen WA, Vieta E, Wittchen HU: ECNP consensus meeting. Bipolar depression. Nice, March 2007. Eur Neuropsychopharmacol 2008 18(7):535-549.

29. Dickerson FB, Boronow JJ, Stallings $C$, Origoni AE, Cole S, Leister F, Krivogorsky B, Yolken RH: The catechol O-methyltransferase Val158Met polymorphism and herpes simplex virus type 1 infection are risk factors for cognitive impairment in bipolar disorder: additive geneenvironmental effects in a complex human psychiatric disorder. Bipolar Disord 2006, 8(2):124-132.

30. Diaz-Asper CM, Goldberg TE, Kolachana BS, Straub RE, Egan MF, Weinberger DR: Genetic variation in catechol-O-methyltransferase: effects on working memory in schizophrenic patients, their siblings, and healthy controls. Biol Psychiatry 2008, 63(1):72-79.

31. Wirgenes KV, Djurovic S, Sundet K, Agartz I, Mattingsdal M, Athanasiu L, Melle I, Andreassen OA: Catechol O-methyltransferase variants and cognitive performance in schizophrenia and bipolar disorder versus controls. Schizophr Res 2010, 122(1-3):31-37.

32. Luteijn F, van der Ploeg FAE: Handleiding Groninger Intelligentietest (GIT). Lisse, The Netherlands; 1983.
33. Wechsler D: Wechsler Adult Intelligence Scale-Revised. New York: Psychological Corporation; 1981.

34. Brand $\mathrm{N}$, Jolles J: Learning and retrieval rate of words presented auditorily and visually. J Gen Psychol 1985, 112(2):201-210.

35. Van der Elst W, Van Boxtel MP, Van Breukelen GJ, Jolles J: Rey's verbal learning test: normative data for 1855 healthy participants aged 24-81 years and the influence of age, sex, education, and mode of presentation. J Int Neuropsycho/ Soc 2005, 11(3):290-302.

36. Eriksen CW, Schultz DW: Information processing in visual search: a continuous flow conception and experimental results. Percept Psychophys 1979, 25(4):249-263.

37. Wechsler D: WAIS-III: Wechsler Adult Intelligence Scale. In. San Antonio: Psychological Corporation; 1997

38. Van Winkel R: Family-based analysis of genetic variation underlying psychosis-inducing effects of cannabis: sibling analysis and proband follow-up. Arch Gen Psychiatry 2011, 68(2):148-157.

39. StataCorp: STATA Statistical Software. In Release 8.0 edn. Texas: College Station; 2002.

40. Snijders TAB, Bosker RJ: Multilevel Analysis, Second edition edn. London: SAGE Publications; 2002.

41. Barnett $J H$, Scoriels L, Munafo MR: Meta-analysis of the cognitive effects of the catechol-O-methyltransferase gene Val158/108Met polymorphism. Biol Psychiatry 2008, 64(2):137-144.

42. Tunbridge EM, Harrison PJ, Weinberger DR: Catechol-o-methyltransferase, cognition, and psychosis: Val158Met and beyond. Biol Psychiatry 2006 60(2):141-151.

43. Mata I, Perez-Iglesias R, Pelayo-Teran JM, Rodriguez-Sanchez JM, GonzalezBlanch C, Carrasco-Marin E, Vazquez-Barquero JL, Crespo-Facorro B: Lack of influence of COMT Val158Met genotype on cognition in first-episode non-affective psychosis. Schizophr Res 2008, 102(1-3):206-209.

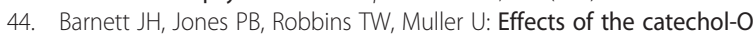
-methyltransferase Val158Met polymorphism on executive function: a meta-analysis of the Wisconsin Card Sort Test in schizophrenia and healthy controls. Mol Psychiatry 2007, 12(5):502-509.

45. Blanchard MM, Chamberlain SR, Roiser J, Robbins TW, Muller U: Effects of two dopamine-modulating genes (DAT1 9/10 and COMT Val/Met) on nback working memory performance in healthy volunteers. Psychol Med 2011, 41(3):611-618.

46. Krabbendam L, Isusi P, Galdos P, Echevarria E, Bilbao JR, Martin-Pagola A, Papiol S, Castano L, Van Os J: Associations between COMTVal158Met polymorphism and cognition: direct or indirect effects? Eur Psychiatry 2006, 21(5):338-342.

47. Burdick KE, Funke B, Goldberg JF, Bates JA, Jaeger J, Kucherlapati R, Malhotra AK: COMT genotype increases risk for bipolar I disorder and influences neurocognitive performance. Bipolar Disord 2007, 9(4):370-376.

48. Buckholtz JW, Sust S, Tan HY, Mattay VS, Straub RE, Meyer-Lindenberg A, Weinberger DR, Callicott JH: fMRI evidence for functional epistasis between COMT and RGS4. Mol Psychiatry 2007, 12(10):893-895. 885

49. Prata DP, Mechelli A, Fu CH, Picchioni M, Toulopoulou T, Bramon E, Walshe M, Murray RM, Collier DA, McGuire P: Epistasis between the DAT 3' UTR VNTR and the COMT Val158Met SNP on cortical function in healthy subjects and patients with schizophrenia. Proc Natl Acad Sci USA 2009, 106(32):13600-13605.

50. Wishart HA, Roth RM, Saykin AJ, Rhodes CH, Tsongalis GJ, Pattin KA, Moore $J H$, McAllister TW: COMT Val158Met Genotype and Individual Differences in Executive Function in Healthy Adults. J Int Neuropsychol Soc 2011, 17(1):174-180

51. Straub RE, Lipska BK, Egan MF, Goldberg TE, Callicott JH, Mayhew MB, Vakkalanka RK, Kolachana BS, Kleinman JE, Weinberger DR: Allelic variation in GAD1 (GAD67) is associated with schizophrenia and influences cortical function and gene expression. Mol Psychiatry 2007, 12(9):854-869.

52. Marenco S, Savostyanova AA, van der Veen JW, Geramita M, Stern A, Barnett AS, Kolachana B, Radulescu E, Zhang F, Callicott JH, et al: Genetic modulation of GABA levels in the anterior cingulate cortex by GAD1 and COMT. Neuropsychopharmacology 2010, 35(8):1708-1717.

53. Tan HY, Chen Q, Sust S, Buckholtz JW, Meyers JD, Egan MF, Mattay VS, Meyer-Lindenberg A, Weinberger DR, Callicott JH: Epistasis between catechol-O-methyltransferase and type II metabotropic glutamate receptor 3 genes on working memory brain function. Proc Natl Acad Sci USA 2007, 104(30):12536-12541. 
54. Nixon DC, Prust MJ, Sambataro F, Tan HY, Mattay VS, Weinberger DR, Callicott JH: Interactive effects of DAOA (G72) and catechol-O -methyltransferase on neurophysiology in prefrontal cortex. Biol Psychiatry 2011, 69(10):1006-1008

55. Opgen-Rhein C, Neuhaus AH, Urbanek C, Hahn E, Sander T, Dettling M: Executive attention in schizophrenic males and the impact of COMT Val108/158Met genotype on performance on the attention network test. Schizophr Bull 2008, 34(6):1231-1239.

56. Bilder RM, Volavka J, Lachman HM, Grace AA: The catechol-O -methyltransferase polymorphism: relations to the tonic-phasic dopamine hypothesis and neuropsychiatric phenotypes. Neuropsychopharmacology 2004, 29(11):1943-1961.

57. Durstewitz D, Seamans JK: The dual-state theory of prefrontal cortex dopamine function with relevance to catechol-o-methyltransferase genotypes and schizophrenia. Biol Psychiatry 2008, 64(9):739-749.

58. Mier D, Kirsch P, Meyer-Lindenberg A: Neural substrates of pleiotropic action of genetic variation in COMT: a meta-analysis. Mol Psychiatry 2010, 15(9):918-927

59. Rasch B, Spalek K, Buholzer S, Luechinger R, Boesiger P, De Quervain DJ, Papassotiropoulos A: Aversive stimuli lead to differential amygdala activation and connectivity patterns depending on catechol-O -methyltransferase Val158Met genotype. Neuroimage 2010, 52(4):1712-1719.

60. Williams LM, Gatt JM, Grieve SM, Dobson-Stone C, Paul RH, Gordon E, Schofield PR: COMT Val(108/158)Met polymorphism effects on emotional brain function and negativity bias. Neuroimage 2010, 53(3):918-925.

61. Lelli-Chiesa G, Kempton MJ, Jogia J, Tatarelli R, Girardi P, Powell J, Collier DA, Frangou S: The impact of the Val158Met catechol- O-methyltransferase genotype on neural correlates of sad facial affect processing in patients with bipolar disorder and their relatives. Psychol Med 2011, 41(4):779-788.

62. Dennis NA, Need AC, LaBar KS, Waters-Metenier S, Cirulli ET, Kragel J, Goldstein DB, Cabeza R: COMT val108/158 met genotype affects neural but not cognitive processing in healthy individuals. Cereb Cortex 2010, 20(3):672-683.

63. Liu B, Song M, Li J, Liu Y, Li K, Yu C, Jiang T: Prefrontal-related functional connectivities within the default network are modulated by COMT val158met in healthy young adults. J Neurosci 2010, 30(1):64-69.

64. Stokes PR, Rhodes RA, Grasby PM, Mehta MA: The Effects of The COMT val (108/158)met Polymorphism on BOLD Activation During Working Memory, Planning, and Response Inhibition: A Role for The Posterior Cingulate Cortex? Neuropsychopharmacology 2011, 36(4):763-771.

65. Liu B, Li J, Yu C, Li Y, Liu Y, Song M, Fan M, Li K, Jiang T: Haplotypes of catechol-O-methyltransferase modulate intelligence-related brain white matter integrity. Neuroimage 2010, 50(1):243-249.

66. Cools R, D'Esposito M: Inverted-U-shaped dopamine actions on human working memory and cognitive control. Biol Psychiatry 2011, 69(12):e113-e125.

67. Cools R: Dopaminergic control of the striatum for high-level cognition. Curr Opin Neurobiol 2011, 21(3):402-407.

68. Barnes SA, Young JW, Neill JC: D(1) receptor activation improves vigilance in rats as measured by the 5 -choice continuous performance test. Psychopharmacology (Berl) 2011, 220(1):129-141.

69. Van Holstein M, Aarts E, Van der Schaaf ME, Geurts DE, Verkes RJ, Franke B, Van Schouwenburg MR, Cools R: Human cognitive flexibility depends on dopamine D2 receptor signaling. Psychopharmacology (Berl) 2011, 218(3):567-578.

70. Kurniawan IT, Guitart-Masip M, Dolan RJ: Dopamine and effort-based decision making. Front Neurosci 2011, 5:81.

71. Aarts E, Van Holstein M, Cools R: Striatal Dopamine and the Interface between Motivation and Cognition. Front Psychol 2011, 2:163.

72. Gamo NJ, Arnsten AF: Molecular modulation of prefrontal cortex: rational development of treatments for psychiatric disorders. Behav Neurosci 2011 125(3):282-296

73. Ursini G, Bollati V, Fazio L, Porcelli A, lacovelli L, Catalani A, Sinibaldi L, Gelao B, Romano R, Rampino A, et al: Stress-related methylation of the catecholO-methyltransferase Val 158 allele predicts human prefrontal cognition and activity. J Neurosci 2011, 31(18):6692-6698.
74. Jacobs E, D'Esposito M: Estrogen shapes dopamine-dependent cognitive processes: implications for women's health. J Neurosci 2011, 31(14):5286-5293.

75. Karlsson S, Rieckmann A, Karlsson P, Farde L, Nyberg L, Backman L: Relationship of dopamine D1 receptor binding in striatal and extrastriatal regions to cognitive functioning in healthy humans. Neuroimage 2011, 57(2):346-351.

doi:10.1186/1471-244X-13-63

Cite this article as: Arts et al:: Antipsychotic medications and cognitive functioning in bipolar disorder: moderating effects of COMT Val ${ }^{108 / 158}$ Met genotype. BMC Psychiatry 2013 13:63.

\section{Submit your next manuscript to BioMed Central and take full advantage of:}

- Convenient online submission

- Thorough peer review

- No space constraints or color figure charges

- Immediate publication on acceptance

- Inclusion in PubMed, CAS, Scopus and Google Scholar

- Research which is freely available for redistribution

Submit your manuscript at www.biomedcentral.com/submit
C) BioMed Central 